A\&L

ISSN 2709-0205

Vol 2 Issue 4 (2021)

https://doi.org/10.47855/ja19020-2021-4

\title{
Cardiovascular risk among people of all ages during the recovery period after COVID-19 (1-3 months) in the background of morbid obesity of the first stage
}

Oleg V. Korkushko, Valentyna P. Chyzhova, Valeri B. Shatilo, Iryna A. Samots, Tetiana I. Kovtonyuk, Anna V. Gavalko

D. F. Chebotarev Institute of Gerontology NAMS of Ukraine, Kyiv, Ukraine

https://doi.org/10.47855/jal9020-2021-4-3

Correspondence: vchizhova@ukr.net

Received: 13.12.2021; Accepted: 04.02.2021; Published: 07.02.2022

\begin{abstract}
The aim of our study is to determine the correlation between obesity and overweight with COVID-19 among people aged over 40 years, in the period from 1 to 3 months after COVID-19 disease. Materials and methods: the group of subjects after COVID-19 consisted of 10 people, including 5 people at the age 40-59 years and 5 people at the age 60 years and older. The control group consisted of 21 individuals without COVID-19 and had a negative PCR test at the time of the survey: 5 individuals aged 40-59 years and 16 individuals aged 60 years and older. The subjects in both groups had cardiovascular risk factors and signs of metabolic syndrome. The subjects have been measured body weight (in $\mathrm{kg}$ ), height (in $\mathrm{cm}$ ), body mass index (BMI, in $\mathrm{kg} / \mathrm{m} 2$ ), waist circumference (WC, in $\mathrm{cm}$ ), hip circumference $(\mathrm{HC}$, in $\mathrm{cm}$ ) with the calculation of the ratio between WC and HC. For the assessment of the state of lipid metabolism, the levels of total cholesterol (TC), high-density lipoprotein cholesterol (HDL-C) and low density lipoprotein cholesterol (LDL-C), triglycerides (TG) in serum venous blood were determined by standard biochemical methods with the help of automatic biochemical analyzer "Autolab" by "Boehringer Mannheim" using the reagents from company "BIO SYSTEMS" (Spain). Cardiovascular risk indicators were calculated - Castelli index (TC/ HDL-C) and Boizel index (TG to HDL-C), and an updated SCORE-2 scale was used. The composition of the physique was determined using the device "OMRON". To exclude organic cardiac pathology, arrhythmias, and conduction, a standard ECG recording on a Ucard 200 device (Ukraine) was used. The microcirculation of the bulbar conjunctiva (slit lamp, "Zeiss", Germany) has been studied. Statistical data processing was performed using the program Statistica 10.0 (USA). Results: in the subjects included in the study, the indicators of general blood tests, which could indicate the presence of inflammation, were without any pathological changes. In accordance with the results of standard ECG, the subjects had no organic cardiac pathology, arrhythmia, and conduction. Younger patients with metabolic syndrome (MS) after COVID-19 had a statistically significantly higher BMI compared with the subgroup without COVID-19. Within each age group, the subjects of both subgroups (excluding COVID-19 and after COVID-19) have had general and visceral obesity rates that were combined with the other markers of metabolic syndrome, including dyslipidemia. It is shown that the calendar age of the patients with overweight after COVID-19 is statistically significantly higher than the calendar age of the patients with the overweight without COVID-19 in the anamnesis. The calendar age of the patients with the obesity of the 1-st grade after COVID-19 was significantly lower than the age of the patients without COVID-19. The indicator of very high cardiovascular risk is determined among the individuals of the senior age group, especially after COVID-19. Patients with high cardiovascular risk have more probabilities for the development of vascular disorders. A close correlation between the
\end{abstract}


number of functioning capillaries and the atherogenicity index $(\mathrm{r}=0.99, \mathrm{p}<0.05)$, as well as with the Castelli index $(\mathrm{r}=0.99, \mathrm{p}<0.05)$ was found. As conclusions, we have found a connection between obesity and an increase of the indicators of cardiovascular risk 3 months later after past COVID-19. It is obvious that among people with obesity a more severe course of COVID-19 is possible at a younger age than among overweight patients. It is likely that COVID-19 may be the cause of accelerated aging in middleaged individuals with obesity. However, to verify this assumption, it is necessary to conduct additional examinations to determine the biological age. The detected changes among the people with MS in 1-3 months after COVID-19 may be the basis for the development of post - COVID syndrome and justify the necessity for comprehensive pathogenetic treatment.

Key words: morbid obesity; COVID-19; cardiovascular risk; Castelli index; Boizel index; SCORE-2 scale; capillaroscopy of the bulbar conjunctiva.

COVID-19 (Corona Virus Disease-19), caused by the SARS-CoV-2 virus, is the biggest epidemiological and clinical-social problem nowadays [1]. The COVID-19 pandemic was declared by the World Health Organization on the 11-th of March 2020 [2]. Coronavirus disease 2019 (COVID-2019) demonstrates a very heterogeneous clinical course and varying degrees of severity of the disease from asymptomatic to lightning-fast deaths. One of the factors that determine the course of the disease is overweight and obesity. Some studies have proven that every fifth hospitalized patient in the Intensive Therapy Unit (ITU) has had obesity [3, 4, 5]. A large UK biobank population analysis even suggests a correlation between the risk of severe COVID-19 disease and an increase in BMI, waist circumference, or waist-to-hip ratio [6]. Other studies also demonstrate higher mortality among the hospitalized patients with obesity and COVID-19 than among those patients who are not obese [7, 8]. To determine the correlation between obesity and overweight with COVID-19, we conducted a study among the people aged over 40 years old between 1 to 3 months after COVID-19 disease.

\section{Materials and methods}

The program of the examination of the patients was developed according to the legislation of Ukraine and principles of the Helsinki Declaration of Human Rights. The patient's consent to participate in the study was confirmed by a signature in the form of informed consent (the examination program, information for the patients, and informed consent form were considered and approved at a meeting of the ethics committee of the Clinical Department of the D.F. Chebotarev Institute of Gerontology, Kyiv, Ukraine (Protocol № 4 of April 12, 2020).

The group of the subjects after COVID-19 consisted of 10 people of different ages. Among them, 4 out of 5 people at the age of 40-59 years and all 5 people aged over 60 years old have had a severe course of the disease and previous hospital treatment. The verification of SARS-CoV-2 has been performed by polymerase chain reaction (PCR) or by antigen test.

The control group consisted of 21 individuals without COVID-19 and had a negative PCR test at the time of the survey. Among them, there were 5 people at the age of 40-59 years old and 16 people aged 60 years and older.

The subjects of both groups have had cardiovascular risk factors and signs of metabolic syndrome (MS). The criteria for MS in accordance to ATP III (2003) were: waist circumference $\geq 102 \mathrm{~cm}$ in men and $\geq 88 \mathrm{~cm}$ in women; high-density lipoprotein cholesterol $<1,03 \mathrm{mmol} / \mathrm{l}$ in men and 1,29 $\mathrm{mmol} / \mathrm{l}$ in women; triglycerides $\geq 1.7 \mathrm{mmol} / \mathrm{l}$; blood pressure level $\geq 130$ / $85 \mathrm{~mm} \mathrm{Hg}$; fasting glucose level $\geq 6.1$ $\mathrm{mmol} / \mathrm{l}$.

The anthropometric measurements had included the determination of body weight (in $\mathrm{kg}$ ), height (in $\mathrm{cm})$, body mass index (BMI, in $\mathrm{kg} / \mathrm{m} 2)$, waist circumference ( $\mathrm{WC}$, in $\mathrm{cm})$, hip circumference $(\mathrm{HC}$, in $\mathrm{cm}$ ). The ratio between WC and HC in men is higher than 0.95 , and in women is more than 0.85 , that is indicating the pathological deposition of fat in the abdominal area.

All subjects had either excess body weight (BMI $25-29.9 \mathrm{~kg} / \mathrm{m}^{2}$ ) or obesity of the 1-st grade (BMI $\left.30-34.9 \mathrm{~kg} / \mathrm{m}^{2}\right)$. 
To assess the state of lipid metabolism, the levels of total cholesterol (TC), high-density lipoprotein cholesterol (HDL-C) and low-density lipoprotein cholesterol (LDL-C), triglycerides (TG) in serum venous blood were determined by standard biochemical methods by automatic biochemical analysis "Autolab" by "Boehringer Mannheim" using reagents from company "BIO SYSTEMS" (Spain). Levels of TC and TG were determined by enzymatic colorimetric method, HDL cholesterol - by the method of precipitation with phosphoric-tungstic acid, the content of LDL cholesterol was calculated by the Friedwald formula $((\mathrm{LDL}-\mathrm{C})=\mathrm{TC}-(\mathrm{HDL}-\mathrm{C})+(\mathrm{TG} / 2.2), \mathrm{mmol} / \mathrm{l})$ [9]. The atherogenicity index was calculated as the ratio of TC to HDL-C.

To determine the risk of the development of cardiovascular disease, we have calculated the cardiovascular risk indicator - Castelli index, as the ratio of TC/ HDL-C, and described Boizel ratio of TG to HDL-C>3, which also correlates with the development of acute coronary complications [ 10-12].

The composition of the physique was determined using the device "OMRON".

To exclude the organic cardiac pathology, arrhythmias, and conduction, a standard ECG recording on a Ucard 200 device (Ukraine) was used.

The microcirculation of the bulbar conjunctiva (slit lamp, "Zeiss", Germany) was studied, followed by processing of the received recordings in the stop-frame mode [13].

The nature of the distribution of the obtained variation series was checked using the ShapiroWilk W test, which testified normal (Gaussian) nature of the data distribution. Therefore, when performing statistical processing of the obtained data using the program Statistica 10.0 (USA), the following methods were used: the calculation of the arithmetical mean and its average error $(\mathrm{M} \pm \mathrm{m})$; assessment of the probability of the difference between the obtained results in the compared groups using the Student's criterion [14].

\section{Results and discussion}

In the subjects included in the study, the indicators of the general blood test, which would indicate the presence of the inflammation, were without any pathological changes, which can be explained by the conducting of the research in the period from 1 to 3 months after acute COVID-19. By the results of standard ECG, the subjects had no organic cardiac pathology, arrhythmia, and conduction.

In the older age group, the subgroup of patients with MS without COVID-19 did not differ from those with MS after COVID-19 in BMI and WC/HC indicators. At the same time, patients of the younger age group with MS after COVID-19 had a statistically significantly higher BMI in comparison with the subgroup of patients without COVID-19 (Tab. 1).

Table 1

Anthropometric parameters in different ages patients with MS depending on COVID-19 status, $\mathrm{M} \pm \mathrm{m}$

\begin{tabular}{|c|l|c|c|c|}
\hline Age groups, years old & COVID-19 status & $\begin{array}{c}\text { Sex, } \\
\text { (women/man) }\end{array}$ & WC/HC & BMI, $\mathrm{kg} / \mathrm{m}^{2}$ \\
\hline \multirow{2}{*}{$40-59$} & Without & $3 / 2$ & $0.90 \pm 0.04$ & $30.80 \pm 1.25$ \\
\cline { 2 - 5 } & After & $4 / 1$ & $0.94 \pm 0.05$ & $34.13 \pm 0.97^{*}$ \\
\hline \multirow{2}{*}{60 and older } & Without & $13 / 3$ & $0.89 \pm 0.02$ & $28.93 \pm 0.85$ \\
\cline { 2 - 5 } & After & $3 / 2$ & $0.94 \pm 0.03$ & $30.46 \pm 1.16$ \\
\hline
\end{tabular}

Note. Significance of the difference between groups: ${ }^{*}-p<0.05$

While analyzing the indicators of the body composition, it was found, that general obesity was combined with visceral obesity (Tab. 2). However, among the younger patients after COVID-19, there was a tendency to a higher percentage of fat content against the background of a slight decrease of skeletal muscle mass in the percentage.

Table 2

Physical characteristics in patients of different ages with MS depending on COVID-19 status, M $\pm m$

\begin{tabular}{|c|l|c|c|c|}
\hline $\begin{array}{c}\text { Age groups, } \\
\text { years }\end{array}$ & COVID-19 status & Body fat content, \% & $\begin{array}{c}\text { Skeletal muscle content } \\
\text { in the body, } \%\end{array}$ & $\begin{array}{c}\text { Visceral fat content in } \\
\text { the body, } \%\end{array}$ \\
\hline \multirow{2}{*}{$40-59$} & Without & $35.35 \pm 3.87$ & $29.10 \pm 2.16$ & $13.75 \pm 2.29$ \\
\cline { 2 - 5 } & After & $42.88 \pm 3.76$ & $25.65 \pm 1.94$ & $12.75 \pm 1.80$ \\
\hline \multirow{2}{*}{60 and older } & Without & $36.65 \pm 3.17$ & $27.62 \pm 1.52$ & $11.62 \pm 0.90$ \\
\cline { 2 - 5 } & After & $35.26 \pm 5.33$ & $28.12 \pm 2.35$ & $13.80 \pm 1.02$ \\
\hline
\end{tabular}

Note. Differences between the groups are not significant 
Within each age group, both subgroups (after COVID-19 and without COVID-19) have had general and visceral obesity rates combined with other markers of metabolic syndrome, including dyslipidemia. Thus, among the individuals of the older age group, after COVID-19, it has been identified a tendency of the increase of concentration of total cholesterol (TC) and triglycerides (TG) in the serum in comparison with a subgroup of people of the same age without COVID-19 in the anamnesis (Tab. 3).

The data analysis of table 3 testifies that the rate of cardiovascular risk (Castelli index) is increased (over 3, [15]) in all subgroups. At the same time, patients with MS of the younger age group after COVID-19 have the highest rate. Although this indicator remains within the reference values, they also have a statistically significant higher Boizel index. Probably, this can be explained by the fact that middle-aged people do not do in time the stratification of the risk of cardiovascular complications and the correction of the modified risk factors (overweight, obesity, prediabetes, etc.). This fact is also testifying about high cardiovascular risk among people with metabolic syndrome, especially among people of middle age.

Table 3

Serum lipid spectrum in patients of different ages with MS depending on COVID-19 status,

$\mathbf{M} \pm \mathbf{m}$

\begin{tabular}{|c|l|c|c|c|c|c|c|c|}
\hline $\begin{array}{c}\text { Age } \\
\text { groups, } \\
\text { years }\end{array}$ & $\begin{array}{c}\text { COVID-19 } \\
\text { status }\end{array}$ & $\begin{array}{c}\mathrm{TC}, \\
\mathrm{mmol} / \mathrm{l}\end{array}$ & $\begin{array}{c}\mathrm{TG}, \\
\mathrm{mmol} / \mathrm{l}\end{array}$ & $\begin{array}{c}\text { HDL-C, } \\
\mathrm{mmol} / \mathrm{l}\end{array}$ & $\begin{array}{c}\text { LDL-C, } \\
\mathrm{mmol} / \mathrm{l}\end{array}$ & $\begin{array}{c}\text { Atherogenicity } \\
\text { index }\end{array}$ & $\begin{array}{c}\text { Castelli } \\
\text { Index } \\
\text { (TC/ } \\
\text { HDL-C) }\end{array}$ & $\begin{array}{c}\text { Boizel } \\
\text { Index } \\
\text { (TG/ HDL- } \\
\mathrm{C})\end{array}$ \\
\hline \multirow{2}{*}{$40-59$} & Without & $5.26 \pm 0.36$ & $0.97 \pm 0.21$ & $1.67 \pm 0.08$ & $3.17 \pm 0.34$ & $2.19 \pm 0.38$ & $3.20 \pm 0.38$ & $0.60 \pm 0.17$ \\
\cline { 2 - 9 } & After & $5.53 \pm 0.32$ & $1.37 \pm 0.19$ & $1.38 \pm 0.12$ & $3.54 \pm 0.33$ & $3.12 \pm 0.44$ & $4.13 \pm 0.44$ & $1.23 \pm 0.15^{*}$ \\
\hline \multirow{2}{6}{$\begin{array}{c}60 \text { and } \\
\text { older }\end{array}$} & Without & $5.56 \pm 0.30$ & $1.07 \pm 0.10$ & $1.54 \pm 0.05$ & $3.45 \pm 0.28$ & $2.57 \pm 0.19$ & $3.33 \pm 0.30$ & $0.75 \pm 0.08$ \\
\cline { 2 - 8 } & After & $5.99 \pm 0.79$ & $1.99 \pm 0.98$ & $1.64 \pm 0.20$ & $3.46 \pm 0.60$ & $2.82 \pm 0.78$ & $3.83 \pm 0.78$ & $1.42 \pm 0.84$ \\
\hline
\end{tabular}

Note. Significance of the difference between groups: ${ }^{*}-p<0.05$

To determine the correlation between overweight and obesity with COVID-19 the groups were redistributed by BMI: $25.0-29.9 \mathrm{~kg} / \mathrm{m}^{2}$ (overweight) and $30.0-34.9 \mathrm{~kg} / \mathrm{m}^{2}$ (obesity of the 1-st degree).

Analysis of table 4 demonstrates that the calendar age of the patients with overweight after COVID-19 is statistically significantly higher than the calendar age of the patients with overweight without COVID-19 in anamnesis. At the same time, among the patients with obesity of the 1-st degree, the picture is the opposite - the calendar age of the patients with COVID-19 is significantly lower than the age of the patients without anamnestic data about suffering from COVID-19. It is obvious that in people with obesity a more severe course of COVID-19 is possible at a younger age than in overweight patients.

Table 4

Calendar age of patients with MS depending on body mass index and COVID-19 status, $\mathrm{M} \pm \mathrm{m}$

\begin{tabular}{|c|l|c|c|}
\hline \multicolumn{1}{|c|}{ BMI, $\left.\mathrm{kg} / \mathrm{m}^{2}\right)$} & COVID-19 status & Age, years & WC/HC \\
\hline $25.0-29.9$ & Without & $68.50 \pm 2.73$ & $0.88 \pm 0.03$ \\
\cline { 2 - 4 } & After & $77.67 \pm 2.60^{*}$ & $0.97 \pm 0.05$ \\
\hline \multirow{2}{*}{$30.0-34.9$} & Without & $64.17 \pm 3.12$ & $0.90 \pm 0.03$ \\
\cline { 2 - 4 } & After & $53.14 \pm 3.88^{*}$ & $0.93 \pm 0.03$ \\
\hline
\end{tabular}

Note. Significance of differences between subgroups of patients without COVID-19 and after COVID-19: *- $p<0.05$ 
The physique indicators of the patients also depended on body mass index and status of COVID-19 (Tab. 5).

Table 5

Bodybuilding indicators in patients with MS depending on body mass index and COVID-19 status, M $\pm m$

\begin{tabular}{|l|l|c|c|c|c|}
\hline BMI, $\mathrm{kg} / \mathrm{m}^{2}$ & COVID-19 status & $\begin{array}{c}\text { Age, } \\
\text { years }\end{array}$ & $\begin{array}{c}\text { Body fat } \\
\text { content, } \%\end{array}$ & $\begin{array}{c}\text { Skeletal muscle } \\
\text { content in the } \\
\text { body, } \%\end{array}$ & $\begin{array}{c}\text { Visceral fat content in } \\
\text { the body, } \%\end{array}$ \\
\hline $25,0-29,9$ & Without & $69.14 \pm 3.06$ & $32.41 \pm 5 ., 20$ & $29.33 \pm 2.57$ & $9.71 \pm 1 ., 17$ \\
\cline { 2 - 6 } & After & $77.69 \pm 2.60$ & $28.10 \pm 5.02$ & $31.10 \pm 2.35$ & $14.33 \pm 1.76$ \\
\hline $30,0-34,9$ & Without & $62.19 \pm 2.56$ & $39.09 \pm 2.21^{*}$ & $27.02 \pm 1.16$ & $13.80 \pm 0.93^{*}$ \\
\cline { 2 - 6 } & After & $53.14 \pm 3.88^{*}$ & $43.92 \pm 2.68^{*}$ & $24.98 \pm 1.42^{*}$ & $12.83 \pm 1.14$ \\
\hline
\end{tabular}

Note. Significance of the difference compared with the corresponding subgroup of overweight patients: ${ }^{*}$ - $p<0,05$

Among the non-COVID-19 patients, with increasing BMI (from the overweight to the obesity of the 1-st grade), the body fat content increases statistically significantly due to an increase of visceral fat content, while the skeletal muscle mass content does not change significantly. At the same time, the people after COVID-19 while increasing BMI (from overweight to the obesity of the 1-st grade), body fat content increases simultaneously with the decreasing of skeletal muscle mass with a tendency to the decreasing of visceral fat content. Table 6.

The indicators of serum lipid composition depending on BMI and COVID-19 status are given in

Among the patients of middle age with COVID-19 and obesity of the 1-st grade, there are the highest levels in blood serum of total cholesterol, triglycerides, LDL-C, and the lowest indicator of HDL$\mathrm{C}$, that is accompanied by a statistically significant increase in atherogenicity index, index Castelli of cardiovascular risk, and increasing of Boizel index.

Table 6

Serum lipid spectra depending on body mass index and COVID-19 status in patients with metabolic syndrome, $\mathrm{M} \pm \mathrm{m}$

\begin{tabular}{|c|c|c|c|c|c|c|c|c|c|}
\hline $\begin{array}{l}\text { BMI, } \\
\mathrm{kg} / \mathrm{m}^{2}\end{array}$ & $\begin{array}{c}\text { COVID- } \\
19 \\
\text { status }\end{array}$ & $\begin{array}{l}\text { Age, } \\
\text { years }\end{array}$ & $\begin{array}{c}\text { TC, } \\
\mathrm{mmol} / \mathrm{l}\end{array}$ & $\begin{array}{c}\text { TG, } \\
\mathrm{mmol} / \mathrm{l}\end{array}$ & $\begin{array}{l}\text { HDL-C, } \\
\mathrm{mmol} / \mathrm{l}\end{array}$ & $\begin{array}{l}\text { LDL-C, } \\
\mathrm{mmol} / 1\end{array}$ & $\begin{array}{c}\text { Atheroge } \\
\text { nicity } \\
\text { index }\end{array}$ & $\begin{array}{l}\text { Castelli } \\
\text { Index } \\
\text { TC/HDL- } \\
\text { C }\end{array}$ & $\begin{array}{l}\text { Boizel } \\
\text { Index } \\
\text { TG/HDL- } \\
\text { C }\end{array}$ \\
\hline $25.0-29.9$ & Without & $69.14 \pm 3.06$ & $5.34 \pm 0.40$ & $1.03 \pm 0.10$ & $1.54 \pm 0.09$ & $3.26 \pm 0.34$ & $2.39 \pm 0.27$ & $2.97 \pm 0.48$ & $0.70 \pm 0.10$ \\
\hline & After & $77.69 \pm 2.60$ & $4.92 \pm 0.73$ & $1.03 \pm 0.05$ & $1.74 \pm 0.01$ & $2.73 \pm 0.72$ & $1.84 \pm 0.44$ & $2.84 \pm 0.44$ & $0.59 \pm 0.03$ \\
\hline $30.0-34.9$ & Without & $62.19 \pm 2.56$ & $5.62 \pm 0.35$ & $1.07 \pm 0.14$ & $1.58 \pm 0.06$ & $3.42 \pm 0.34$ & $3.48 \pm 0.23$ & $3.58 \pm 0.23$ & $0.69 \pm 0.11$ \\
\hline & After & $53.14 \pm 3.88^{*}$ & $6.12 \pm 0.46$ & $1.96 \pm 0.67$ & $1.41 \pm 0.10$ & $3.83 \pm 0.30$ & $3.46 \pm 0.48^{*}$ & $4.47 \pm 0.48^{*}$ & $1.71 \pm 0.64$ \\
\hline
\end{tabular}

Note. Significance of the difference between groups: ${ }^{*}-\mathrm{p}<0.05$ 
An updated SCORE-2 scale is also used for the assessment of cardiovascular risk [16]. According to the indicators of age, the average blood pressure, measured on an outpatient basis, and the indicator of non-HDL, which is equal to the difference between the levels of TC and HDL-C, the individual risks were determined for each subject and in different age groups (Tab. 7).

A very high cardiovascular risk is found among individuals of the older age group, especially after COVID-19.

Table 7

Indicator of total cardiovascular risk according to the updated SCORE-2 scale depending on the age and COVID-19 status, $\mathrm{M} \pm \mathrm{m}$

\begin{tabular}{|c|l|c|c|}
\hline $\begin{array}{c}\text { Age groups of patients, } \\
\text { years old }\end{array}$ & \multicolumn{1}{|c|}{ COVID-19 status } & non-HDL & Risk \\
\hline \multirow{2}{*}{$40-59$} & Without & $3.60 \pm 0.44$ & $3.67 \pm 0.33$ \\
\cline { 2 - 4 } & After & $4.15 \pm 0.34$ & $3.00 \pm 0.84$ \\
\hline 60 and older & Without & $4.27 \pm 0.32$ & $17.00 \pm 2.37^{*}$ \\
\cline { 2 - 4 } & After & $4.35 \pm 0.87$ & $21.60 \pm 4.43^{*}$ \\
\hline
\end{tabular}

Note. Significance of the difference between groups: ${ }^{*}-p<0.05$

The patients with a high cardiovascular risk are more likely to have the development of vascular disorders, for the visualization of which we have used capillaroscopy of the bulbar conjunctiva.

In the subjects with COVID-19 in the anamnesis, the diameter of the arterioles decreases, and the diameter of the venules increases, which leads to a decrease of the arterio-venular coefficient. In the individuals after COVID-19, the number of functioning capillaries per unit in the area of the conjunctiva decreases, and as a result of this, avascular areas appear, especially in the perilimbal area. Besides this, the manifestations of perivascular edema and delayed blood flow increase. A close correlation was found between the number of functioning capillaries and the atherogenicity index ( $r=0.99, p<0.05)$, as well as with the Castelli index $(r=0.99, \mathrm{p}<0.05)$. During the capillaroscopy, the lipid layers were observed.

After COVID-19 among the elderly people in all parts of the microcirculatory tract (venules, arterioles, capillaries) there was revealed the violations of microhemodynamics in the form of increased unevenness of vascular caliber and the presence of their tortuosity (especially venules), the presence of the spasm of arterioles and dilatation of venules with a decrease of arteriole-venular coefficient up to 1:4 1:6 and less. These changes were observed among half of the respondents after COVID-19.

The extravascular changes in the microcirculatory tract after COVID-19 among the elderly people are represented by isolated microhemorrhages, as well as by moderate perivascular edema.

The intravascular changes of the microcirculatory tract predominate in the group of people after COVID-19 and are characterized by the presence of a sludge syndrome, which occurs in arterioles, postcapillary venules, and capillaries, often with a circulatory block and micro thrombosis (Fig.). 


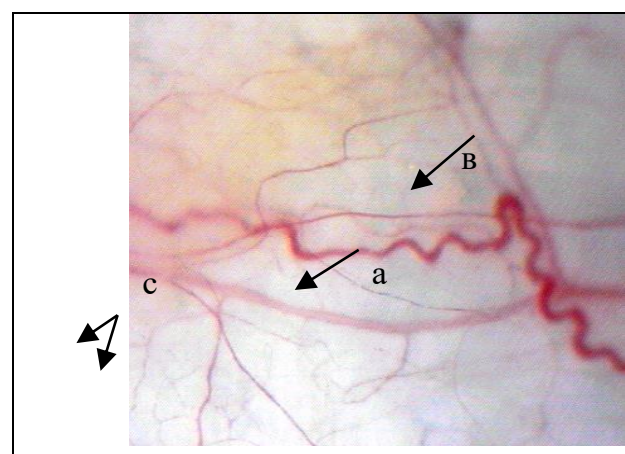

a - arterioles, в - venules, c- capillaries

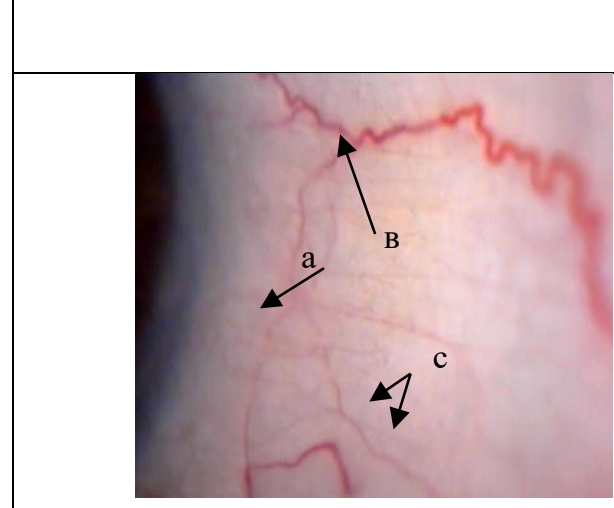

$\mathrm{a}$ - arterioles, в - venules, $\mathrm{c}$ - capillaries

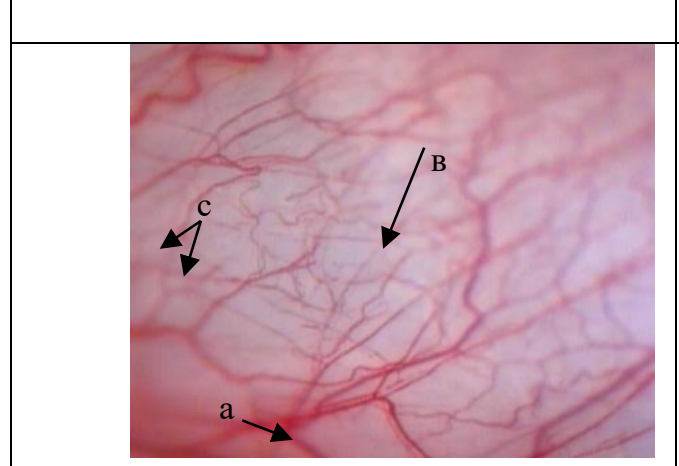

$\mathrm{a}$ - arterioles, $\mathrm{B}$ - venules, c- capillaries

B

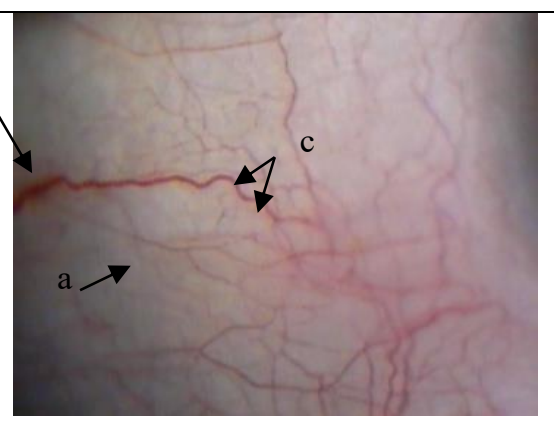

$\mathrm{a}$ - arterioles, в- venules, c- capillaries

\section{Example 1. Average age without COVID-19.}

\section{Patient M., 54 years old.}

The ratio of the arterioles and corresponding venules diameters is 1:3, the caliber of the vessels is uneven, the architecture is preserved, the arterioles are spasmodic, venules are atonic, there is a sludge phenomenon in the arterioles and capillaries. There are lipid inclusions. capillaries.

Blood flow is granular, slow by $1 \mathrm{~mm}^{2}$ in the 11 functioning

Example 2. Elderly without COVID-19.

Patient K., 68 years old.

The ratio of the arterioles and corresponding venules diameters 1:4-1:5, the caliber of the vessels is uneven, there is a pronounced mesh structure of blood vessels, there is a sludge phenomenon in the arterioles and capillaries. There are lipid inclusions.

Blood flow is homogeneous-granular, slow by $1 \mathrm{~mm}^{2}$ in the 10 functioning capillaries.

\section{Example 3. Average age with MS after COVID-19.}

Patient C., 51 years old.

The ratio of the arterioles and corresponding venules diameters is 1:3, the caliber of the vessels is uneven, arterioles are spasmodic, venules are atonic, there is a sludge phenomenon in the arterioles and capillaries. Pericapillary edema is pronounced. There is a capillary micro thrombosis.

Blood flow is granular, slow by $1 \mathrm{~mm}^{2}$ in the 11 functioning capillaries.

\section{Example 4. Elderly with MS after COVID-19.}

\section{Patient S., 74 years old.}

The ratio of the arterioles and corresponding venules diameters 1:4- 1:5, the caliber of the vessels is uneven, there is a pronounced mesh structure of blood vessels, there is a sludge phenomenon in the arterioles and capillaries. Pericapillary edema is pronounced. There is a capillary micro thrombosis.

Blood flow is homogeneous-granular, slow by $1 \mathrm{~mm}^{2}$ in the 8 functioning capillaries.

Figure. Vessels capillaroscopy of the bulbar conjunctiva in different ages patients in vivo (vital). 
Thus, we have found a correlation between the presence of obesity and an increase of the indicators of cardiovascular risk 3 months later after COVID-19. COVID-19 may likely be the reason for accelerated aging in middle-aged individuals with obesity. However, to verify this assumption, it is necessary to conduct additional examinations with the determination of the biological age.

\section{Conclusions}

1. The patients of the middle age after COVID-19 have a higher BMI due to an increase of body fat with a decrease of skeletal muscle mass.

2. The patients of the middle age with the obesity of the 1-st grade in 1-3 months later after COVID19 have a high indicator of cardiovascular risk (Castelli index). The patients of the older age group after COVID-19 have a very high cardiovascular risk on the SCORE-2 scale.

3. During the post COVID period in the patients with obesity the architecture of the vessels of the microcirculatory tract is changed, the narrowing of the arterioles is combined with the decrease of the number of functioning capillaries.

4. The detected changes in the people with MS in 1-3 months after they have had COVID-19 may be the basis for the development of the post-COVID syndrome and justify the need for comprehensive pathogenetic treatment.

Author Contributions: All authors participated equally in writing this article.

Conflicts of Interest: The authors declare no conflict of interest.

\section{Information about Authors:}

Oleg V. Korkushko - DSc (Medicine), Prof., Cor. Member of the NAS of Ukraine, Full Member of the NAMSof Ukraine, Head of the Department of Clinical Physiology and Pathology of Internal Organs; https://orcid.org/00000001-6577-8647

Valentyna P. Chyzhova - DSc (Medicine), Chief Researcher, Head of the Department of Clinical Physiology and Pathology of Internal Organs; https://orcid.org/0000-0002-2282-2975

Valeri B. Shatilo - DSc (Medicine), Prof., Chief Researcher, Head of the Department of Clinical Physiology and Pathology of Internal Organs, Deputy Director for Research; https://orcid.org/0000-00016420-000X

Iryna A. Samots - Researcher of the Department of Clinical Physiology and Pathology of Internal Organs; https://orcid.org/ 0000-0002-4256-6155

Tetiana I. Kovtonyuk - Junior Researcher of the Department of Clinical Physiology and Pathology of Internal Organs

Anna V. Gavalko - Junior Researcher of the Department of Clinical Physiology and Pathology of Internal Organs 


\section{References}

1. Illi, B.; Vasapollo, B.; Valensise, H.; Totta, P. SARS-CoV-2, Endothelial Dysfunction, and the Renin-Angiotensin System (RAS): A Potentially Dangerous Triad for the Development of PreEclampsia. Reprod Med 2021, 2, 95-106. https://doi.org/10.3390/reprodmed2020010

2. Zheng, M.; Gao, Y.; Wang, G. et al. Functional exhaustion of antiviral lymphocytes in COVID-19 patients. Cell Mol Immunol 2020, 17, 5, 533-535. https://doi.org/10.1038/s41423-020-0402-2 PMID:32203188

3. Schetz, M.; De Jong, A.; Deane, A. M.; Druml, W.; Hemelaar, P.; Pelosi, P. et al. Obesity in the critically ill: a narrative review. Intensive Care Med 2019, 45, 757-769. https://doi.org/10.1007/s00134019-05594-1

4. De Jong, A.; Verzilli, D.; Jaber, S. ARDS in obese patients: specificities and management. Crit Care 2019, 23, p 74. https://doi.org/10.1186/s13054-019-2374-0

5. Ryan, D. H.; Ravussin, E.; Heymsfield, S. COVID 19 and the Patient with Obesity - The Editors Speak Out. Obesity (Silver Spring) 2020, 28, 847-847. https://doi.org/10.1002/oby.22808

6. Zhu, Z.; Hasegawa, K.; Ma, B.; Fujiogi, M.; Camargo, C. A.; Liang, L. Association of obesity and its genetic predisposition with the risk of severe COVID-19: analysis of population-based cohort data. Metabolism 2020, 112, 154345. https://doi.org/10.1016/j.metabol.2020.154345

7. Yates, T.; Zaccardi, F.; Islam, N.; Razieh, C.; Gillies et al. Obesity, Ethnicity, and Risk of Critical Care, Mechanical Ventilation, and Mortality in Patients Admitted to Hospital with COVID-19: analysis of the ISARIC CCP-UK. Cohort. Obesity (Silver Spring) 2021, 29, 1223-1230.

https://doi.org/10.1002/oby.23178

8. Thomson, R. J.; Hunter, J.; Dutton, J.; Schneider, J.; Khosravi, M. et al. Clinical characteristics and outcomes of critically ill patients with COVID-19 admitted to an intensive care unit in London: a prospective observational cohort study. PLoS ONE 2020, 15, e0243710.

https://doi.org/10.1371/journal.pone.0243710

9. Friedewald, W. T.; Kevy, I. R.; Fredrickson, D. S. Estimation of the concentration of low-density lipoprotein cholesterol in plasma, without the use of the preparative ultracentrifuge. Clin Chem 1972, $18,499-502$.

10. Baez-Duarte, B. G.; Zamora-Gínez, I.; González-Duarte, R.; Torres-Rasgado, E.; Ruiz-Vivanco, G.; Pérez-Fuentes, R.; Celis TMRGOD. Triglyceride/high-density lipoprotein cholesterol (TG/HDL-C) index as a reference criterion of risk for metabolic syndrome (MetS) and low insulin sensitivity in apparently healthy subjects. Gac Med Mex 2017, 153, 2, 152-158. PMID: 28474700

11. Baez-Duarte, B. G.; Sánchez-Guillén, M. D. C.; Pérez-Fuentes, R. et al. $\beta$-cell function is associated with metabolic syndrome in Mexican subjects. Diabetes Metab Syndr Obes 2010, 3, 301-309. https://dx.doi.org/10.2147\%2FDMSOTT.S12375

12. Salazar, M. R.; Carbajal, H. A.; Espeche, W. G.; Aizpurúa, M.; Dulbecco, C. A.; Reaven, G. M. Comparison of two surrogate estimates of insulin resistance to predict cardiovascular disease in apparently healthy individuals. Nutr Metab Cardiovasc Dis 2017, 27, 4, 366-373.

https://doi.org/10.1016/j.numecd.2016.12.002

13. Malaya, L. T. Microcirculation in cardiology. Malaya, L. T.; Miklyaev, I. Yu.; П.Г Kravchun, P. G., Eds. High school: Kharkiv, 1977, p 232. (in Russian)

14. Moskalenko, V. F.; Gulchiy, O. P; Colubchikov, M. V. Biostatistika. Knigaplus: Kyiv, 2009, p. 184. (in Ukrainian)

15. Louie, J. K.; Acosta, M.; Samuel, M. C.; Schechter, R.; Vugia, D. J.; Harriman, K.; Matyas, B. T.; California Pandemic (H1N1) Working Group. A novel risk factor for a novel virus: obesity and 2009 pandemic influenza A (H1N1). Clin Infect Dis 2011, 52, 3, 301-312. https://doi.org/10.1093/cid/ciq152 16. Visseren, F. L. J.; Mach, F.; Smulders, Y. M.; Carballo, D.; Koskinas, K. C. et al. 2021 ESC Guidelines on cardiovascular disease prevention in clinical practice. Eur Heart J 2021, 42, 3227-3337. https://doi.org/10.1093/eurheartj/ehab484

17. Sun, Y.; Wang, Q.; Yang, G.; Lin, C.; Zhang, Y.; Yang, P. Weight and prognosis for influenza A(H1N1)pdm09 infection during the pandemic period between 2009 and 2011: a systematic review of 
observational studies with meta-analysis. Infect Diseases 2016, 48, 813-22.

https://doi.org/10.1080/23744235.2016.1201721 